\title{
Mobilidade pendular e integração regional: uma metodologia de análise para as regiões metropolitanas de Belo Horizonte, Rio de Janeiro e São Paulo
}

\author{
Commuting and regional integration: an analytical \\ methodology for the metropolitan regions \\ of Belo Horizonte, Rio de Janeiro and São Paulo
}

Carlos Lobo

Leandro Cardoso

Ivania Linhares de Almeida

\section{Resumo}

Não é raro, na literatura acadêmica, haver controvérsias sobre os limites e a configuração das regiões metropolitanas no Brasil. Afora a falta de critérios na definição desses recortes regionais, parece relevante considerar o significado e a abrangência da mobilidade pendular na dinâmica populacional regional. 0 objetivo deste artigo é investigar o nível de integração dos municípios periféricos que integram as regiões metropolitanas de Belo Horizonte, Rio de Janeiro e São Paulo. Utilizando-se dos microdados amostrais do Censo Demográfico de 2010, foi proposto o Índice de Integração Metropolitana, agregado das Razões de Pendularidade Interna, Conectividade Pendular e Pendularidade Nuclear. Em geral, os resultados indicaram sensíveis diferenças regionais, para além do esperado efeito da variável distância, permitindo identificar casos de baixo nível de integração.

Palavras-chave: integração metropolitana; mobilidade pendular; regiões metropolitanas; Belo Horizonte; Rio de Janeiro; São Paulo.

\begin{abstract}
The existence of controversies in the academic literature about the limits and configuration of metropolitan regions in Brazil is not uncommon. Apart from the criteria's lack of precision in the definition of these regional outlines, it seems relevant to consider the meaning and scope of commuting in the regional population dynamics. The objective of this article is to investigate the level of integration of the peripheral municipalities that are part of the metropolitan regions of Belo Horizonte, Rio de Janeiro and São Paulo. Using microdata samples from the 2010 Demographic Census, the Metropolitan Integration Index was proposed, aggregating Internal Pendularity Ratios, Pendular Connectivity and Nuclear Pendularity. In general, the results indicated sensitive regional differences beyond the expected effect of the distance variable, allowing to identify cases of low integration levels.
\end{abstract}

Keywords: metropolitan integration; commuting; metropolitan regions; Belo Horizonte; Rio de Janeiro; São Paulo. 


\section{Introdução}

A indefinição no estabelecimento de critérios objetivos e claros para a criação e delimitação territorial das nove primeiras Regiões Metropolitanas (RMs) brasileiras, institucionalizadas sob um regime autoritário e centralizador durante a década de 1970, ainda não foi superada, nem mesmo com a promulgação da Constituição Federal de 1988. Não obstante seu caráter democrático e federativo, que transformou os municípios em entes com maior autonomia e concedeu às unidades da federação o poder de criar suas próprias RMs, a Carta Magna brasileira não estabeleceu as diretrizes específicas para a institucionalização dessas regiões. $\mathrm{Na}$ verdade, essa lacuna se reflete no descompasso entre a real configuração do tecido metropolitano e a dinâmica social e econômica regional efetiva, o que, não raro, cria ou amplia os obstáculos à gestão e ao planejamento territorial integrados, bem como a implantação de políticas públicas regionais eficazes, capazes de oferecer maior eficiência e qualidade à própria mobilidade espacial da população.

Em janeiro de 2015 foi sancionada a lei federal 13.089, denominada Estatuto da Metrópole. Trata-se de uma importante conquista, que representou um marco regulatório para suprir o vácuo deixado pela Constituição de 1988, no que diz respeito tanto às diretrizes para a criação das RMs, quanto ao planejamento, gestão e governança interfederativa nas RMs e Aglomerações Urbanas (AUs) do País. Ainda que os dispositivos do Estatuto da Metrópole pudessem ser úteis ao entendimento da nova estrutura de gestão das funções públicas de interesse coletivo, há ainda obstáculos para a efetiva implementação das diretrizes gerais de institucionalização regional, especialmente aqueles de natureza política, que não raro definem os limites e a configuração de cada RM.

Com efeito, entre os critérios que tradicionalmente servem de parâmetro para a identificação do território metropolitano, destacam-se os chamados movimentos pendulares, que permitem estimar a intensidade e as características dos fluxos populacionais no espaço metropolitano, refletindo vários aspectos da dinâmica e da organização do mercado laboral e educacional, incluindo a emersão e/ou consolidação de novas centralidades urbanas. A mobilidade pendular metropolitana configura-se, portanto, como um indicador altamente sensível ao grau de integração municipal no espaço regional. Reflete, dessa forma, a própria densidade social e econômica do espaço metropolitano. No caso das Regiões Metropolitanas de Belo Horizonte (RMBH), Rio de Janeiro (RMRJ) e São Paulo (RMSP), assim como nos principais aglomerados metropolitanos no Brasil, os deslocamentos diários de população têm sido resultantes, em várias circunstâncias, do movimento do capital imobiliário junto às ações seletivas do Estado na dotação de infraestruturas urbanas e programas habitacionais, que têm expandido as áreas de deslocamentos diários para periferias cada vez mais distantes do core metropolitano. 0 objetivo deste trabalho é, diante desse contexto, avaliar, com base em indicadores padronizados e agregados, extraídos da matriz origem e destino dos fluxos pendulares metropolitanos, o nível de integração dos municípios periféricos que compõem as três maiores RMs do Sudeste brasileiro: RMBH, RMRJ E RMSP. Diante desse propósito, foram utilizados os microdados amostrais do Censo 
Demográfico de 2010, tendo como base as variáveis que identificam o município de residência na data de referência do recenseamento e aquele de trabalho e/ou de estudo.

Importa ressaltar que a análise da configuração metropolitana vai além da necessidade de uma possível revisão do recorte regional legalmente estabelecido. Envolve uma reflexão mais ampla sobre a redefinição das diretrizes de ação do público, bem como das políticas de gestão e planejamento metropolitano. Os diferentes níveis de integração municipal no espaço metropolitano frequentemente refletem arranjos territoriais gerais e específicos, identificados, por exemplo, pela intensidade e pela natureza da mobilidade populacional no espaço metropolitano, ou pelas necessidades locacionais estruturais, ou mesmo pelas opções que envolvem escolhas pessoais.

\section{A integração municipal metropolitana: conceito e significado dos movimentos pendulares}

A mobilidade pendular define-se, grosso modo, como o movimento realizado pela população que se desloca entre determinadas unidades espaciais de origem e destino, frequentemente municípios, delimitadas pelo seu local de residência e pelo local em que trabalha e/ou estuda. Além de não serem de fácil definição, a mobilidade pendular envolve e/ou está relacionada a outras formas de mobilidade, como a residencial. Conforme esclarecem Jardim e Ervatti (2007, p. 7),
A mobilidade residencial refere-se aos deslocamentos da população no interior de uma determinada unidade administrativa tendo como unidade mínima de referência o município, pelo fato que a mudança de residência não implica, necessariamente, mudança de emprego ou atividade.

A mobilidade pendular caracteriza-se como um dos fenômenos típicos da realidade metropolitana que, como destacou Jardim (2011), reflete diretamente na produção do espaço metropolitano e indica, do ponto de vista social e geográfico, a emersão de novas centralidades urbanas. Como sugerem Moura, Branco e Firkowski (2005), a intensidade da pendularidade populacional constitui-se como um importante indicador da extensão da urbanização no território, sendo uma informação útil à delimitação de grandes áreas urbanas (zonas de conurbação). 0 próprio Bureau do Censo dos Estados Unidos, desde a década de 1960, utiliza o movimento pendular por motivo de trabalho na delimitação de grandes conjuntos metropolitanos. ${ }^{1}$ Conforme estabelecido no Bureau (1967, p. 3),

The general concept of a metropolitan area is one of a integrated economic and social unit with a recognized large population nucleus. [...] One of the basic criteria for measuring economic integration to determine whether additional counties should be included in an area definition, is the relationship of place of residence to place of work, involving outlying counties and the county of the central city. The volume of worked commuting was determined on the basis of data from the 1960 census of population. 
Ainda que seja conceitualmente distinta dos movimentos migratórios, que envolvem, entre outros aspectos, a mudança deliberada do local de residência, a mobilidade pendular apresenta reflexos e efeitos similares demograficamente, uma vez que a unidade espacial de referência experimenta um acréscimo populacional temporário, que pode ser significativo em determinados momentos do dia. Como destaca Aranha (2005, p. 96),

Do ponto de vista demográfico, os deslocamentos pendulares modificam provisoriamente o volume populacional do município e aumentam ou diminuem seu tamanho dependendo das características de cada área. Assim, se o município for mais concentrador ou mais dispersor, os deslocamentos podem gerar maior ou menor demanda por serviços ou bens ou aumentar sua oferta para a população residente.

Se alguns municípios se "beneficiam" do aumento provisório da população, dado o incremento da demanda de vários serviços locais, outros apresentam uma condição bem diferenciada fora do turno laboral, o que os definiria como as conhecidas "cidades-dormitório". Em geral, essas cidades são caracterizadas pela infraestrutura urbana precária, parcelamentos irregulares e alto volume de trabalhadores pouco qualificados; são marcadas por uma "paisagem dominada por moradias inacabadas, produto da autoconstrução ou mutirão, é algo bastante conhecido nas periferias das metrópoles brasileiras" (Lobo, 2016b, p. 290). ${ }^{2}$ De acordo com Ojima, Silva e Pereira (2007, p. 126), pode-se supor que "que o padrão de cidades-dormitório com baixo dinamismo econômico só passa a existir quando a proporção de movimentos pendulares é mais elevada, em torno de $40 \%$ da população ocupada".3

A definição de região metropolitana como recorte para execução de políticas públicas, de acordo com Cruz (2010), apresenta obstáculos tendo em vista a existência de expressivas diferenças internas, inclusive no nível de coesão entre os municípios metropolitanos. Para o autor, nesse mesmo trabalho, existe um impasse em relação à unidade adequada para o planejamento no âmbito metropolitano. Ainda que exista uma tendência de, nos espaços mais adensados, os relacionamentos com o core metropolitano serem mais intensos, o adensamento territorial potencializa as relações sociais e econômicas no espaço metropolitano, o que pode ter efeito na redução dos custos de transportes e na expansão da infraestrutura, dinamizando a mobilidade espacial da população. ${ }^{4}$ Pode-se, sobre esse aspecto, considerar que a pendularidade seja uma consequência da mobilidade metropolitana, determinada pela expansão dos vetores de expansão do tecido urbano para além do core metropolitano. ${ }^{5}$ Isso reflete escolhas residenciais de segmentos da população na expectativa de que externalidades positivas compensem os custos adicionais da distância ao trabalho ou, no caso dos trabaIhadores de baixa renda, a ação excludente do mercado imobiliário e/ou do mercado de trabaIho (Brito e Souza, 2005). ${ }^{6}$

Há, todavia, como descrevem Pereira e Herrero (2009, p. 22), "fluxos pendulares do tipo puro desconcentração produtiva" que indicam "um possível processo de integração metropolitana multipolarizada, reforçando a dinamização de subcentros econômicos da região e apontando novos eixos de expansão urbana e demanda viária". ${ }^{7}$ Ao avaliar o caso 
francês, analisando as áreas metropolitanas de Paris, Lyon e Marseille, Aguilera (2005) observou que, ao longo da última década, as mudanças na localização dos empregos e das pessoas levaram a um crescimento do emprego, ainda que tivesse ocorrido uma queda no número de trabalhadores residentes. Os resultados obtidos por esse autor, nesse mesmo trabalho, permitiram identificar um crescimento no número de viagens de deslocamento entre os subcentros e entre alguns municípios localizados fora da área metropolitana, elevando a distância média de deslocamento.

De acordo com Lobo (2016b), de modo geral, a análise sobre a mobilidade pendular no Brasil, identificada pelo Censo Demográfico de 2010, permite demonstrar dois pontos centrais de conclusões:

$\left.1^{\circ}\right)$ há um importante incremento na mobilidade pendular envolvendo as principais metrópoles brasileiras e os municípios de suas respectivas Unidades da Federação; $2^{\circ}$ ) que esse crescimento foi predominantemente direcionado para as periferias metropolitanas, embora tenha ocorrido um crescimento no volume e no número de municípios mais distantes que abrigam populações que trabalham ou estudam no core metropolitano. (Lobo, 2016b, p. 296)

Com base nos dados referentes à mobilidade pendular na RMBH, utilizando as bases dos censos demográficos de 2000 e 2010, no nível de centralidade e de dispersão espacial metropolitana, Lobo et al. (2015) observaram uma pequena redução na proporção dos fluxos diários do tipo residência/trabalho no sentido periferia/núcleo e um crescimento mais expressivo, tanto absoluto como relativo, dos deslocamentos na direção núcleo/periferia (denominados pendularidade inversa). Como exemplo, verifica-se que o município de Confins teve um acréscimo superior a $300 \%$. Destacam-se, ainda, tanto em termos relativos como absolutos, Nova Lima e Betim, que apresentaram incrementos em torno de $50 \%$. As evidências sugerem que parece ocorrer o fortalecimento de determinadas centralidades além do core metropolitano, que tem induzido uma mobilidade ampliada no espaço metropolitano (Lobo et al., 2015).

Verifica-se, em geral, que o core metropolitano, mesmo que a mobilidade na periferia tenha experimentado um incremento considerável nas últimas décadas, mantém sua influência como fornecedora de postos de trabalho e de serviços, principalmente para os municípios da periferia imediata (municípios limítrofes ou mais próximos). A pendularidade pode servir, portanto, como um importante parâmetro de apoio à gestão da mobilidade laboral metropolitana. Como indicador-síntese da interação socioeconômica entre municípios, a pendularidade retrata, em boa medida, a mobilidade da força de trabalho e da população em atividade escolar, não raro, consideradas variáveis definidoras do nível de polarização e influência regional (Castello Branco, Firkowski e Moura, 2005; Duranton, 2013; Ojima, 2011). 


\section{0 índice de integração metropolitana: uma metodologia proposta}

Utilizando a divisão político-administrativa municipal e a base de dados dos microdados amostrais do Censo Demográfico de 2010, ${ }^{8}$ por meio da identificação do município de residência e daquele de trabalho e de frequência à escola (ou creche) ${ }^{9}$ foi possível estimar os volumes e estabelecer os vetores dos ditos movimentos pendulares intermunicipais. Obteve-se, dessa forma, uma matriz de origem-destino, dados de deslocamentos pendulares para fins de trabalho ou de estudo, o que permitiu identificar não apenas os fluxos que envolviam o núcleo metropolitano, mas também os deslocamentos entre os municípios periféricos. Essa matriz tornou possível elaborar um conjunto de indicadores, bem como um índice sintético agregado denominado Índice de Integração Metropolitana (IIM), cujo propósito foi representar o nível de integração regional dos municípios metropolitanos.

O IIM foi derivado da combinação de três outros indicadores, denominados: Razão de Pendularidade Interna (Equação 1), Razão de Conectividade Pendular (Equação 2) e Razão de Pendularidade Nuclear (Equação 3), obtidos pelas seguintes equações:

$$
\text { (Equação 1) RPI }=\sum_{1}^{n} \frac{M P i_{i j}}{M P e_{i j}}
$$

em que,

$M P i_{i j}=$ movimentos pendulares envolvendo município i e $j$, ambos pertencentes à RM (deslocamentos internos);
$M P e_{i j}=$ movimentos pendulares com origem no município $i$ (pertencente à RM) e destino o município $j$ não pertencente à RM (deslocamentos para fora da RM);

$$
\text { (Equação 2) } \mathrm{RCP}=\sum_{1}^{n} \frac{C P e_{i j}}{C P p_{i j}}
$$

em que,

$C P e_{i j}=$ número de conexões efetivas do município $i$ na região $j$ (conexões municipais efetivas internas);

$C P p_{i j}=$ número de conexões possíveis do município $i$ na região $j$ (total de municípios da RM menos um);

$$
\text { (Equação 3) RPN }=\sum_{1}^{n} \frac{M P n_{i j}}{P t e m_{i j}}
$$

em que,

$M P n_{i j}=$ movimentos pendulares envolvendo município i para o núcleo metropolitano na região $j$ (deslocamentos internos com destino ao NM);

Ptem $_{i j}=$ população que trabalha ou estuda no município $i$ na região $j$.

A mobilidade pendular foi considerada como variável proxi, definidos os indicadores de Pendularidade Interna (PI), Conectividade Pendular (CP) e Pendularidade Nuclear (PN), que representam três diferentes dimensões do nível de integração regional: $1^{\text {a }}$ ) o peso da integração intrametropolitana comparado ao da extrametropolitana; $2^{\text {a }}$ ) o nível de conectividade de cada município metropolitano com os demais; e $3^{a}$ ) o nível de interação com o núcleo metropolitano, comparado ao peso da população que não faz pendularidade (trabalha e estuda no próprio município). 
Os indicadores citados (RPI, RPC e RPN) foram padronizados, obtidos pela razão entre a diferença entre o $i$-ésimo valor e a média sobre o desvio padrão regional. Como resultado, têm-se as Razões Padronizadas (PIp, CPp e PNp), conforme expressões (4), (5) e (6).

$$
\begin{aligned}
& \text { (4) } P I p=\frac{R P N_{i j}-\mu}{\sigma} \\
& \text { (5) } C P p=\frac{R C P I_{i j}-\mu}{\sigma} \\
& \text { (6) } P N p=\frac{R N I_{i j}-\mu}{\sigma}
\end{aligned}
$$

$R_{i N_{i j}} R C P I_{i j}$ e $R N I_{i j}=$ Razões de cada indicador no município $i$ na região $j$;

$\mu=$ média regional do indicador $\omega$, para o município $i$ na região $j$

$\sigma=$ desvio padrão do indicador $\omega$, para o município $i$ na região $j$.

Os valores padronizados definiram o IIM, dado pela média aritmética dos indicadores regionais. Em seguida, fez-se a conversão na escala de 0 a 1 (0 para o valor mais baixo e 1 para o mais elevado), conforme descrito na expressão (7):

$$
\text { (7) } I I M=\frac{C M_{i j}-C M \min _{i j}}{C M \max _{i j}-C M \min _{i j}}
$$

$C M i_{j}=$ razão padronizada do indicador $\omega$, para o município $i$ na região $j$;

$C M \min _{i j}=$ razão padronizada mínima do indicador $\omega$, para o município $i$ na região $j ;$ $C M m a x_{i j}=$ razão padronizada máxima do indicador $\omega$, para o município $i$ na região $j$;

Para fins de análise e interpretação, os resultados foram representados em cartogramas específicos, cujos valores do IIM e dos indicadores padronizados (PI $p$, CP $p$ e PN $p$ ) foram agrupados em quatro classes utilizando-se do método "quebra natural", também conhecido como distribuição de Jenks (Natural Break ou Natural Break Points). ${ }^{10}$ As classes foram denominadas "Muito Baixa", "Baixa", "Média" e "Alta", e os valores foram compreendidos entre os intervalos <-1; entre -1 e 0 ; de 0 a 1; e $>1$ $\sigma$, para o Pl $p, \mathrm{CP} p$ e PN $p$ e em intervalos iguais para o IIM (de 0 a 0,25; 0,25 a 0,5; 0,5 a 0,75; e de 0,75 a 1 , respectivamente).

\section{Os indicadores de pendularidade regional: os diferentes níveis de integração regional nas RMs de Belo Horizonte, Rio de Janeiro e São Paulo}

Ao analisar os resultados referentes aos valores de IIMs, observam-se sensíveis diferenças nos níveis de integração do conjunto de municípios das três RMs avaliadas. Conforme dados expostos na Figura 1, nota-se maior frequência relativa de municípios periféricos com nível muito baixo de integração regional na RMRJ (30\%), ainda que seja, dentre as três RMs, aquela com menor número de municípios. Na RMSP, a proporção nessa classe muito baixa é de $21,05 \%$. Nessa mesma RM, destaca-se, ainda, a proporção daqueles classificados como média integração $(47,37 \%)$. $\mathrm{Na}$ RMBH chama a atenção aqueles municípios considerados como de baixa e muito baixa integração (eles, em ambas as classes, envolvem $60,61 \%$ da RM). Na RMSP prevalece o nível médio de integração, com quase $50 \%$ dos casos. 
Figura 1 - Distribuição percentual dos municípios da RMBH, RMRJ e RMSP, conforme níveis de integração municipal (IIM) em 2010

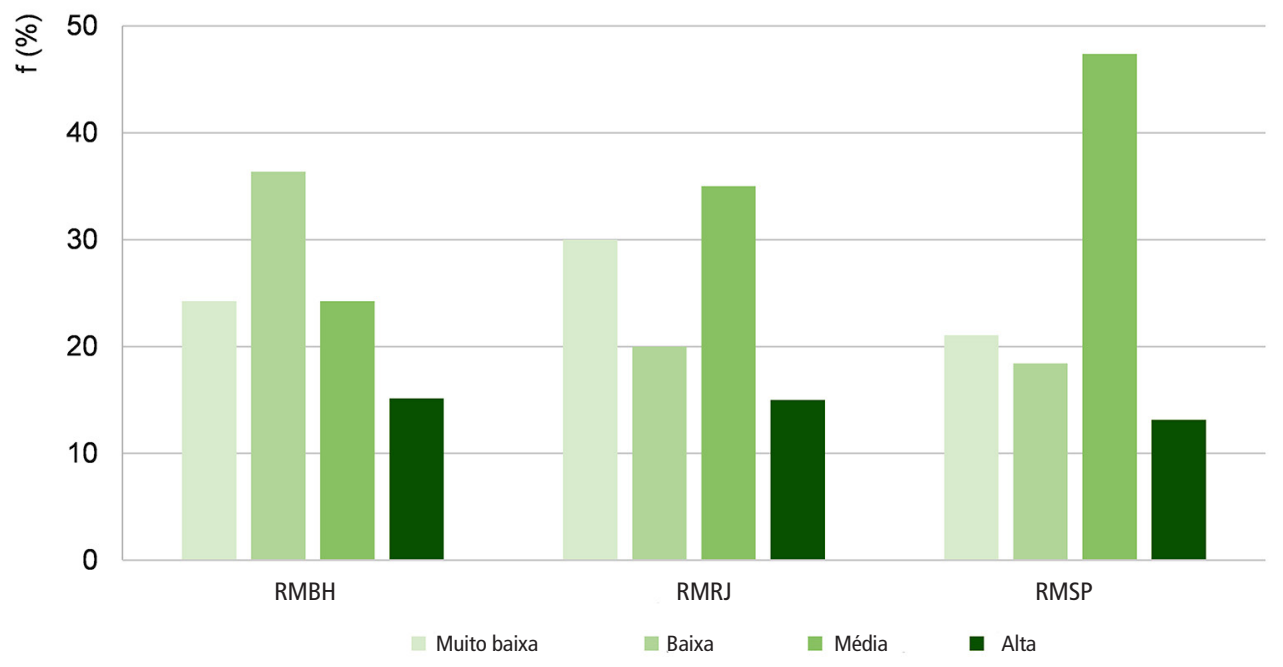

Fonte: Censo Demográfico de 2010 (dados da amostra).

Como esperado, em todas as regiões os municípios mais próximos, especialmente aqueles limítrofes ao core metropolitano, apresentam, em sua grande maioria, maior coesão regional. Contudo, afora esse padrão geral, notam-se particularidades na distribuição regional da mobilidade pendular. Como pode ser observado pela Figura 2, enquanto o maior nível de coesão na RMBH e na RMRJ ocorre com os municípios vizinhos localizados ao norte das respectivas capitais, na RMSP se destacam aqueles a leste e oeste. Os municípios classificados como de alta coesão são Ribeirão das Neves, Vespasiano, Santa Luzia (Norte); Sabará (Leste); Ibirité (Sul); Florestal e Mateus Leme (Oeste); Itatiaiuçu, Rio Manso e Itaguara (Sul); Baldim, Jaboticatubas e Nova União (Norte) na RMBH; Mesquita, Nilópolis e São João de Meriti (Norte); Itaguaí e Paracambi (Noroeste); Rio
Bonito, Tanguá, Cachoeiras de Macacu e Guapimirim na RMRJ; e Embu e Taboão da Serra (Oeste); São Caetano do Sul (Leste); Ferraz de Vasconcelos e Poá (Nordeste); Juquitiba e São Lourenço da Serra (Sudoeste); Vargem Grande Paulista (Oeste); Pirapora do Bom Jesus e Cajamar (Noroeste); Santa Isabel, Guararema e Salesópolis (Nordeste) na RMSP.

Ainda como representado na Figura 2, aqueles municípios com menor integração regional, que foram classificados como de muito baixa integração metropolitana, conforme valores de IIMs, concentram-se nos extremos norte e sudoeste da RMBH, leste e oeste da RMRJ e noroeste/sudoeste e nordeste da RMSP. Os municípios que integram essa classe são Baldim, Jaboticatubas e Nova União (Norte); Florestal e Mateus Leme (Sudoeste); Itatiaiuçu, Rio Manso e Itaguara (Sul) na RMBH; Paracambi 
e Itaguaí (Oeste); Guapimirim, Cachoeiras de Macacu, Rio Bonito e Tanguá (Leste) na RMRJ; e São Lourenço da Serra e Juquitiba (Sudoeste); Vargem Grande Paulista (Oeste); Pirapora do Bom Jesus e Cajamar (Noroeste); Santa Isabel, Guararema e Salesópolis (Leste), na RMSP. Do grupo de municípios que apresentam muito baixo nível de integração, três são limítrofes ao núcleo de cada RM: Cajamar e Juquitiba, em São Paulo, e Itaguaí, no Rio de Janeiro.

Ao avaliar de modo desagregado os indicadores padronizados de Pendularidade Interna (PI), Conectividade Pendular (CP) e Pendularidade Nuclear (PN) também é possível observar determinadas particularidades regionais. $\mathrm{Na}$ RMBH, cujos índices estão representados na Figura 3, chama a atenção os casos dos municípios de Itatiaiuçu e Santa Luzia, que foram classificados, respectivamente, como de muito baixa e alta integração em todos os três indicadores. Há, todavia, maiores semelhanças nos padrões espaciais de RP e PN, o que sugere o poder de centralização da capital mineira. Para esses dois índices, a maior interação ocorre nos municípios dos vetores norte, nordeste (ambos fortemente conectados com o core metropolitano, sobretudo pela presença da chamada Linha Verde, corredor viário composto pelas avenidas dos Andradas e Cristiano Machado e pela rodovia MG-10, que se apresenta como um facilitador de acesso à Regional Venda Nova - uma importante centralidade situada no vetor norte da capital, a qual atrai um elevado contingente de cidadãos metropolitanos diariamente, para fins de trabalho, estudo, consumo, etc.) e sul (especialmente ao longo do eixo rodoviário da rodovia Fernão Dias, que se afigura como o principal vetor industrial e de escoamento da produção da RMBH). Em relação ao indicador
$\mathrm{CP}$, parece haver relação mais direta com a distância em relação ao Núcleo Metropolitano (NM), com destaque para a menor força dos municípios dos extremos nordeste e sudoeste, cujas conexões são restritas a uma rede local.

Na RMRJ, o município de São João de Meriti, localizado ao norte da Capital fluminense, apresenta alto nível de integração regional, observados os valores de PI $p$, CP $p$ e PN $p$ (Figura 4). Situado na Baixada Fluminense, é considerado uma cidade-dormitório e apresenta uma elevada densidade demográfica (cerca de $13.000 \mathrm{hab} . / \mathrm{km}^{2}$ ), o que propicia o "fornecimento" de elevados contingentes de trabaIhadores para o core metropolitano, sobretudo por se tratar de uma região com um limitado dinamismo econômico. Além disso, São João de Meriti é cortado pela rodovia Presidente Dutra, que 0 interliga a outros pontos do Estado, 0 que vem demonstrar, a exemplo do que se verifica na $\mathrm{RMBH}$, que o provimento de acessibilidade favorece a integração e, em última análise, a "vitalidade metropolitana". Em contrapartida, Cachoeiras de Macacu apresenta situação oposta - baixo nível nos três indicadores. Se a distância e/ou recorte litorâneo (baía de Guanabara) estabelecem condicionantes geográficos menos favoráveis à integração com a periferia leste/nordeste, chama a atenção a tênue coesão metropolitana dos municípios de Itaguaí e Paracambi, localizados na zona oeste da RM.

0 padrão de integração no caso da RMSP, mais intenso conforme a observação de menores distâncias (as exceções com maior interação na periferia norte são: Caieiras, Franco da Rocha e Francisco Morato), é claramente concentrado no sentido leste/oeste (Figura 5), no qual há elevada densidade do sistema rodoviário 
Figura 2 - Índice de Integração Municipal (IIM) na periferia das regiões metropolitanas de Belo Horizonte, Rio de Janeiro e São Paulo, 2010

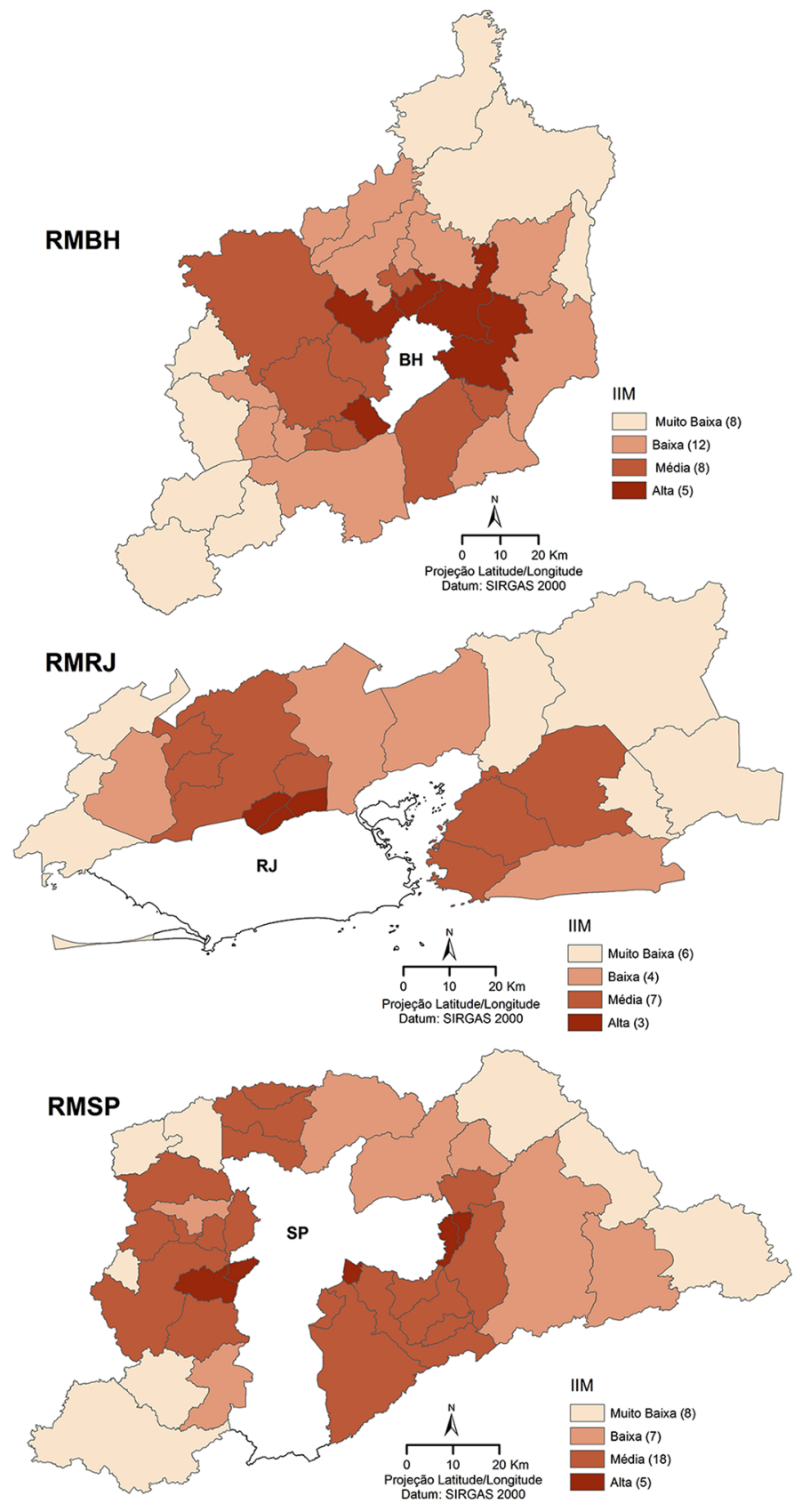

Fonte: Censo Demográfico de 2010 (dados da amostra). 
Figura 3 - Índices padronizados de Pendularidade Interna $\left(\mathrm{PI}_{\mathrm{p}}\right)$, Conectividade Pendular $\left(\mathrm{CP}_{\mathrm{p}}\right)$ e Pendularidade Nuclear $\left(\mathrm{PN}_{\mathrm{p}}\right)^{\mathrm{p}}$ na periferia da Região Metropolitana de Belo Horizonte - 2010

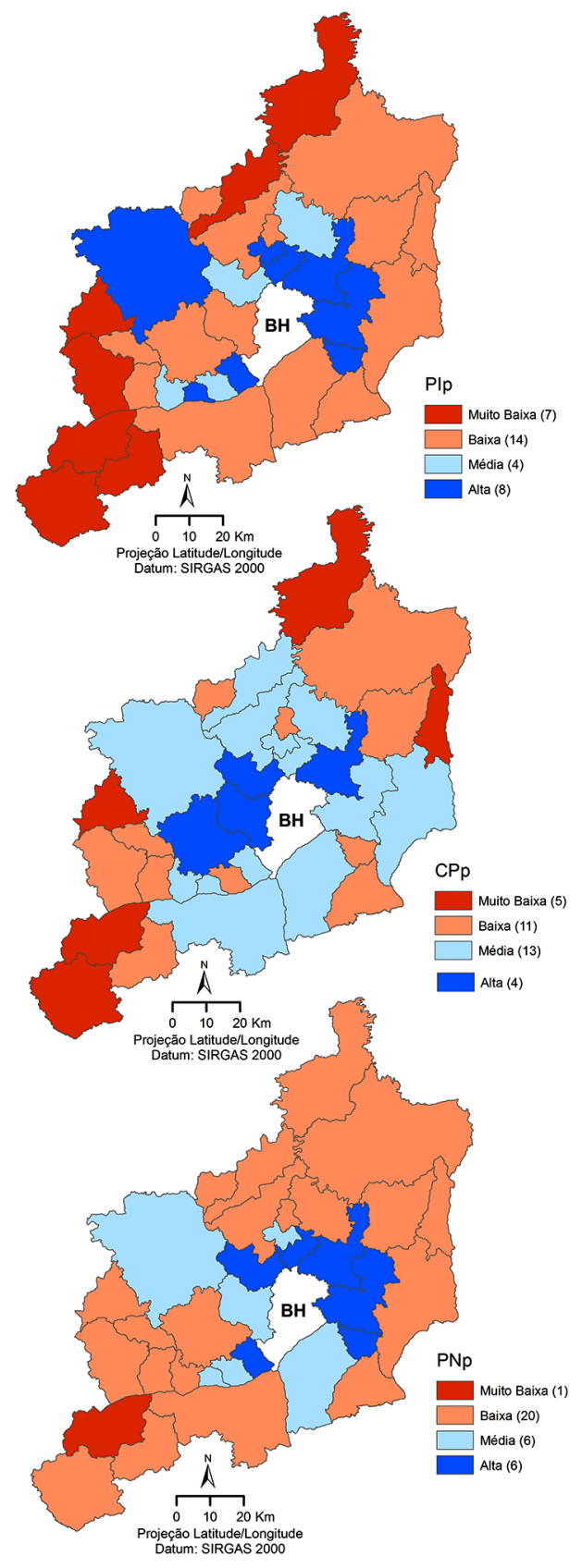

Fonte: Censo Demográfico de 2010 (dados da amostra). 
Figura 4 - Índices padronizados da Pendularidade Interna $\left(\mathrm{PI}_{\mathrm{p}}\right)$, Conectividade Pendular $\left(\mathrm{CP}_{\mathrm{p}}\right)$ e Pendularidade Nuclear $\left(\mathrm{PN}_{\mathrm{p}}\right)$ na periferia da Região Metropolitana do Rio de Janeiro - 2010

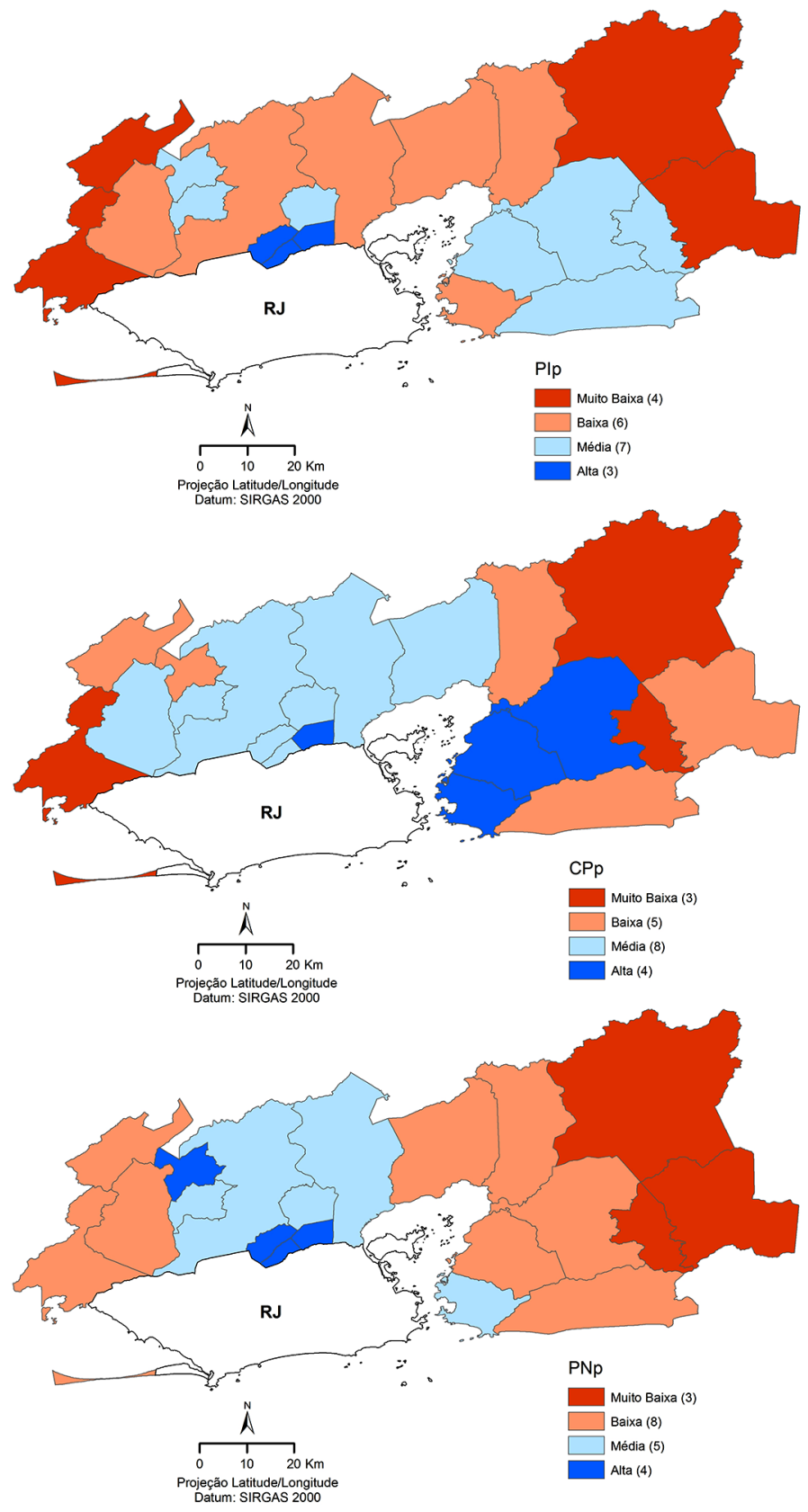

Fonte: Censo Demográfico de 2010 (dados da amostra). 
Figura 5 - Índices padronizados da Pendularidade Interna $\left(\mathrm{PI}_{\mathrm{p}}\right)$, Conectividade Pendular $\left(\mathrm{CP}_{\mathrm{p}}\right)$ e Pendularidade Nuclear $\left(\mathrm{PN}_{\mathrm{p}}\right)$ na periferia da Região Metropolitana de São Paulo - 2010
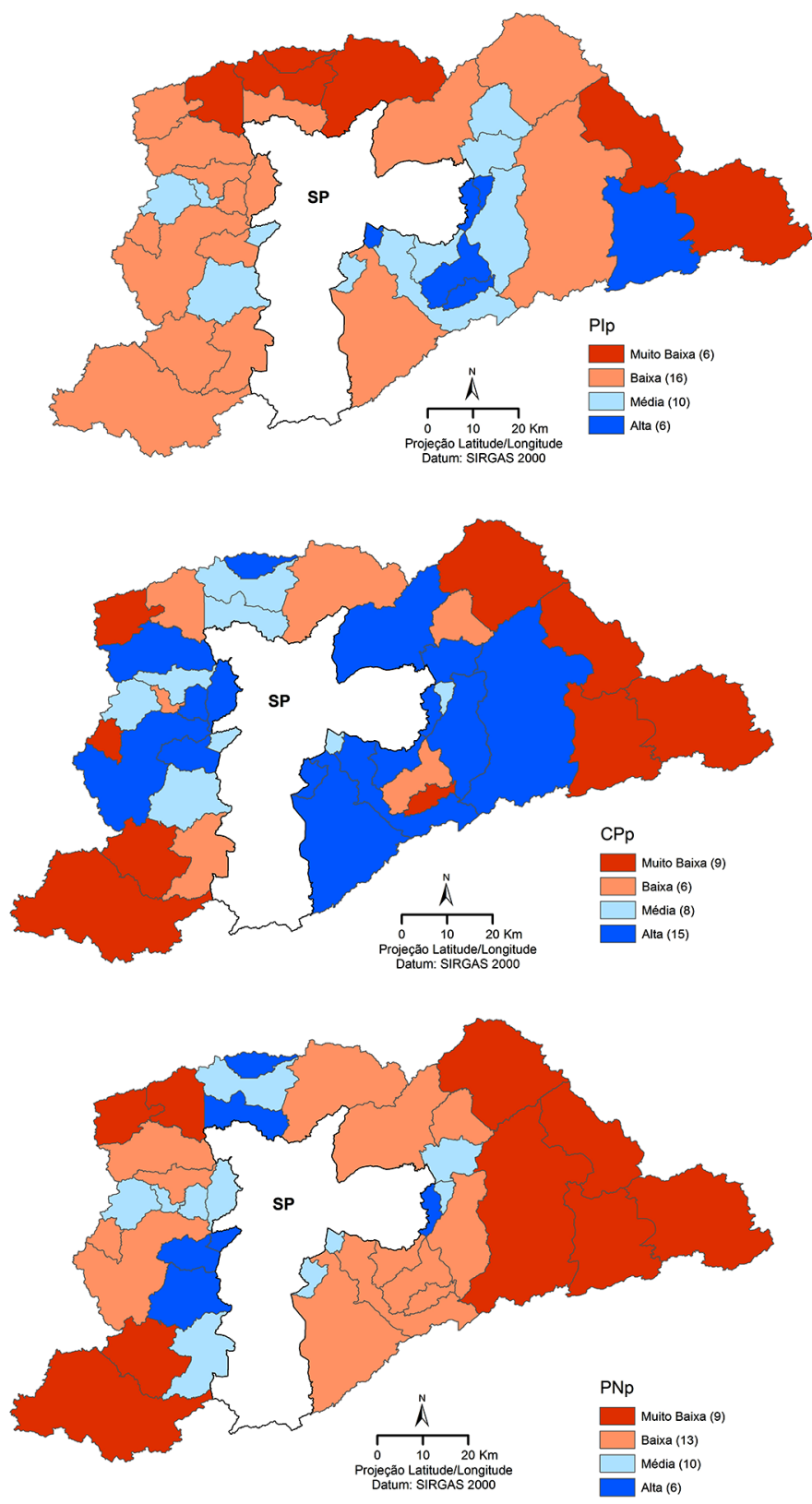

Fonte: Censo Demográfico de 2010 (dados da amostra). 
e metroferroviária metropolitano. Se, em um extremo, Ferraz de Vasconcelos apresenta alto nível de integração nesses três indicadores (potencializado, principalmente, pelo seu dinamismo industrial, o que atrai trabalhadores de municípios vizinhos), Guararema e Salesópolis (extremo leste) foram classificados como muito baixo nos três índices avaliados. Como ocorre nas outras três RMs, na RMSP valores mais elevados ocorrem na distribuição dos índices de Conectividade Pendular. Os parâmetros são menores quando comparados os fluxos internos e externos, dados os valores de PI (o que também é comum para as demais RMs).

Os resultados mostram, portanto, a existência de vários municípios que, apesar de legalmente integrarem as respectivas RMs, apresentam baixo nível de integração regional, em especial os casos já citados de Itatiaiuçu/ RMBH, São João de Meriti/RMRJ e Ferraz de Vasconcelos/RMSP. Há, contudo, outros casos não menos relevantes, em que a mobilidade sugere uma integração metropolitana bastante tênue, como aqueles que apresentaram nível muito baixo em dois indicadores e baixo em um terceiro, quais sejam: Baldim, Florestal e Itaguara (RMBH); Rio Bonito e Itaguaí (RMRJ); Santa Isabel, Cajamar, Pirapora do Bom Jesus, São Lourenço da Serra e Juquitiba (RMSP). Nesses casos a integração extrametropolitana parece ser bem mais relevante.

\section{Considerações finais}

Não obstante as naturais incertezas e recorrentes controvérsias que envolvem a análise da dinâmica populacional em âmbito regional, torna-se necessário maior investimento na análise do significado e da abrangência dos movimentos espaciais da população no espaço metropolitano, seja dos fluxos migratórios intermunicipais seja mesmo da denominada mobilidade pendular. As regiões metropolitanas de Belo Horizonte, Rio de Janeiro e São Paulo, ainda que apresentem condições comuns a boa parte das RMs do País, dada a própria magnitude representada pelos volumes consideráveis de população envolvida, compreendem espaços peculiares, com conjuntura social e econômica característica da macrorregião central do território nacional.

Especialmente a partir de década de 1980, vários municípios das periferias metropolitanas apresentaram níveis de crescimento populacional significativamente superiores aos seus respectivos núcleos. Se os sinais de dispersão espacial da população residente são insuficientes para caracterizar um quadro típico de desconcentração espacial (Lobo, 2016a), como proposto em modelos clássicos da economia regional, há sinais de ganho de autossuficiência ou dinamismo econômico em diversos espaços periféricos, que induzem novas centralidades além do core metropolitano, como os dados de mobilidade pendular parecem indicar. A prevalência das chamadas "cidades-dormitório" não parece ser uma realidade típica da periferia metropolitana na atualidade.

Os resultados apresentados neste trabaIho, que buscaram avaliar o nível de integração municipal na periferia metropolitana das RMs de Belo Horizonte, Rio de Janeiro e São Paulo, podem ser sintetizados em três grandes conclusões gerais: $1^{\text {a) }}$ para além da esperada relação entre a integração metropolitana e a proximidade em relação ao core, os diferentes padrões espaciais indicam uma associação com as 
características regionais, especialmente aquelas decorrentes de atividades e condições econômicas locais; $2^{\text {a)}}$ ) alguns municípios, incluindo aqueles limítrofes ao NM, que atualmente integram as respectivas RMs, apresentam nível muito baixo de integração regional, extrapolando os reais limites que poderiam definir 0 "real" espaço metropolitano; e $3^{a}$ ) há municípios em que a integração metropolitana vai além de uma simples ação de polarização do núcleo, o que sugere a difusão de novas centralidades regionais.

Ainda que a interpretação dos resultados apresentados deva ser contraposta às especificidades dos casos e aos limites inerentes ao recorte temporal avaliado (análise cross-section), bem como à abrangência do significado dos movimentos pendulares como proxi da integração metropolitana, parece razoável que há diferenças sensíveis que definem a complexa realidade metropolitana, cuja heterogeneidade compromete a conformação de uma região geográfica homogênea. Contudo, torna-se relevante uma revisão mais profunda e acurada do que é chamado genericamente metropolitano no País, incluindo seu significado com região. Essa controvérsia requer, como sugere Ojima (2016), a próprio recorte metropolitano a priori. Esse autor, nesse mesmo trabalho, indica duas opções: 1) predefinir o limite territorial (município A, região metropolitana B, etc.) e buscar analisar a dispersão urbana e os deslocamentos populacionais dentro desse recorte; ou 2) estabelecer, com base nos deslocamentos populacionais, a extensão do território que deverá ser considerado como o recorte de estudo. Isso significa considerar que a dispersão urbana não deve ser entendida apenas como a expansão da mancha urbanizada, mas deve ser repensada para que se compreendam os processos de ocupação e a sua forma.

Para Araújo e Holzer (2016), o fenômeno do espraiamento metropolitano e sua dinâmica não se restringem a variáveis demográficas e à urbanização contínua. Aspectos como mudanças implícitas no processo de organização socioespacial e os mecanismos de ação e seus agentes e a forma como impactam a formação de uma nova paisagem precisam ser investigados. A reflexão não deve, portanto, ater-se de forma restrita à redefinição da configuração territorial e à atualização do recorte regional (simples exclusão de um município), mas às características e à dinâmica que configuram novas espacialidades que se consolidam em torno das principais metrópoles do País. Alguns municípios poderiam ser reclassificados dentro de áreas de transbordo da polarização metropolitanas? Ou definiriam novas áreas de influência de outros polos regionais para além do core metropolitano? Há ainda aqueles casos em que uma forte integração se estende para além dos limites metropolitanos, a exemplo do município de Sete Lagoas em Minas Gerais. Essas são apenas algumas questões que não devem ser ignoradas, nem esquecidas na agenda no debate político nacional. 


\section{Carlos Lobo}

Universidade Federal de Minas Gerais, Instituto de Geociências, Programa de Pós-Graduação em Geografia, Programa de Pós-Graduação em Análise e Modelagem de Sistemas Ambientais. Belo Horizonte, MG/Brasil.

carlosfflobo@gmail.com

\section{Leandro Cardoso}

Universidade Federal de Minas Gerais, Departamento de Engenharia de Transportes e Geotecnia, Programa de Pós-Graduação em Geotecnia e Transportes. Belo Horizonte, MG/Brasil.

leandro@etg.ufmg.br

\section{Ivania Linhares de Almeida}

Conselho Regional de Engenharia e Agronomia de Minas Gerais. Belo Horizonte, MG/Brasil. ivanialinhares@gmail.com

\section{Agradecimentos}

Ao CNPq e à Fapemig pelo auxílio financeiro aos projetos de pesquisa. Cabe ainda menção ao apoio oferecido pela Fapemig por meio da concessão de bolsa de pesquisa pelo Programa Pesquisador Mineiro.

\section{Notas}

(1) Como descrevem Morrill, Comartie e Hart (1999, p. 730), "Over the years, the Census Bureau and $O M B$ have tweaked and added to the standards for defining metropolitan areas, making them complex and unwieldy. Besides the obvious and logical criterion of commuting, the standards include what are behaviorally irrelevant rules - namely, that under certain circumstances the metropolitan area must have at least 100,000 people, that outlying counties must meet highly complex combinations of density and urbanization". Na França, o Institut Natitonal de la Statistique et des Etudes Economiques usa esse mesmo indicador na identificação de polarização de uma área urbana (Julien, 2000).

(2) Há, como esclarece Ojima (2010, p. 398), "uma associação quase que imediata do processo de metropolização ao surgimento das 'cidades-dormitório', baseado no modelo dicotômico 'centro-periferia'”.

(3) Com base no percentual da população economicamente ativa ocupada, entre 15 a 64 anos, que se desloca para o núcleo metropolitano, pode-se considerar alguns exemplos de municípios-dormitório da RMBH, a exemplo de Ibirité (51\%), Ribeirão das Neves (57\%), Sabará (63\%), Santa Luzia (50\%) e Vespasiano (49\%), conforme dados do Censo Demográfico de 2010 (Ojima et al., 2010). 
(4) Para Frey e Speare Jr. (1992), essas transformações na forma de assentamento definiriam um novo conceito de "área metropolitana", como forma ampliada de vida local, caracterizada por alta densidade de pendularidade. O debate sobre o movimento é, portanto, indissociável da noção de mobilidade, que vai caracterizar-se como um importante aspecto da vida urbana atual, acentuando a importância dos transportes, especialmente o individual (Moura, Branco e Firkowski, 2005).

(5) Frequentemente, a mobilidade ocorre entre municípios relativamente próximos e/ou limítrofes, envolvendo trajetos de curta distância, com menor tempo de deslocamento. Em municípios que não contam com vias/estradas de boa qualidade ou com meios de transporte pouco eficientes, com trechos com alto grau de congestionamento, dada a existência de áreas de alta densidade populacional, a mobilidade apresenta baixo nível de eficiência, com velocidades de deslocamento baixas.

(6) A pendularidade também envolve outro tipo de configuração da mobilidade urbana: aquela que diz respeito às famílias/pessoas de alta renda que residem nos chamados condomínios fechados e se deslocam diariamente para outros municípios para trabalhar ou estudar. Trata-se de um fenômeno, dentre outros aspectos, decorrente da busca por uma melhor qualidade de vida, especialmente por esperadas amenidades ambientais, incluindo a suposta condição de menor violência urbana, além de menores índices de congestionamentos viários e de poluição, em municípios de menor porte. É um movimento essencialmente residencial, sem, contudo, haver alteração no local de trabalho, que redefine novos vetores de mobilidade metropolitana.

(7) Souza e Brito (2008) analisaram o processo de expansão urbana de Belo Horizonte e da Região Metropolitana de Belo Horizonte (RMBH) em direção ao município de Ribeirão das Neves. Tendo como fonte de dados os censos demográficos de 1991 e 2000 e as pesquisas origem e destino de 1992 e 2002, os resultados apresentados indicaram que essa expansão urbana em direção a Ribeirão das Neves não se relaciona ao dinamismo econômico do município, mas sim a um processo de exclusão de Belo Horizonte. Isso ocorre devido ao fato de Ribeirão das Neves atrair um grande contingente populacional, principalmente por meio da dinâmica de seu mercado imobiliário, caracterizado por um alto grau de informalidade. Nesse trabalho, com base na Pesquisa OD (2002), esses autores observaram que 70\% dos trabalhadores de Ribeirão das Neves moravam anteriormente em Belo Horizonte, e 30\% trabalhavam informalmente na capital mineira.

(8) As Regiões Metropolitanas de Belo Horizonte, Rio de Janeiro e São Paulo, conforme divisão políticoadministrativa utilizada no Censo Demográfico de 2010, compreendiam, respectivamente, um total de 34, 21 e 39 municípios, (incluindo os núcleos metropolitanos).

(9) Os municípios de trabalho e/ou estudo, discriminados no Censo Demográfico de 2010, foram combinados para tornar possível a comparação com os outros dois recenseamentos. Para tanto, quando foram declarados municípios distintos de trabalho e estudo prevaleceu o primeiro (de trabalho).

(10) O método da quebra natural de Jenks tem como objetivo encontrar os intervalos de classes com o propósito de minimizar a variância interna, identificando as maiores diferenças entre os limites de cada uma. Assim, procura-se por agrupamentos que ocorram "naturalmente" nos dados, buscando uma homogeneidade interna para cada classe. Portanto, por meio dessa metodologia, o mapa de probabilidade pode ser interpretado como um mapa que foi divido em 5 classes que possuem probabilidades estimadas semelhantes (Albuquerque, 2008). 


\section{Referências}

AGUILERA, A. (2005). Growth in commuting distances in French Polycentric Metropolitan Areas: Paris, Lyon and Marseille. Urban Studies, v. 42, n. 9, pp.1537-1547.

AlBuquerque, P. H. M. (2008). Conglomerados espaciais: uma nova proposta. Dissertação de Mestrado. Belo Horizonte, Universidade Federal de Minas Gerais.

ARANHA, V. (2005). Mobilidade pendular na metrópole paulista. São Paulo em Perspectiva. São Paulo, v. 19 , n. 4 , pp. $96-109$.

ARAÚJO, E. C. de e HOLZER, W. (2016). “Dispersão urbana e planejamento urbano regional: inquietações". In: OJIMA, R. e MARANDOLA Jr, E. Dispersão urbana e mobilidade populacional. São Paulo, Blucher.

BRITO, F. e SOUZA, J. de (2005). Expansão urbana nas grandes metrópoles: o significado das migrações intrametropolitanas e da mobilidade pendular na reprodução da pobreza. São Paulo em Perspectiva. São Paulo, v. 19, n. 4, pp. 48-63.

CASTELLO BRANCO, M. L. G. (2003). Espaços urbanos: uma proposta para o Brasil. Rio de Janeiro, IBGE.

CASTELLO BRANCO, M. L. G.; FIRKOWSKI, O. L. F. C. e MOURA, R. (2005). Movimento pendular: abordagem teórica e reflexões sobre o uso do indicador. In: XI ENCONTRO NACIONAL DA ANPUR. Anais. Salvador.

CRUZ, M. F. (2010). Condicionantes Metropolitanos para Políticas Públicas: Análise dos Transportes Coletivos na Região Metropolitana de São Paulo (1999-2009). Dissertação de Mestrado. São Paulo, Fundação Getúlio Vargas.

DESCHAMPS, M.; DELGADO, P.; MOURA, R. e CASTELLO BRANCO, M. L. (2007). Nível de integração dos municípios à dinâmica metropolitana. Curitiba, Ipardes.

DURANTON, G. (2013). Delineating metropolitan areas: Measuring spatial labour market networks through commuting patterns. Processed, Pennsylvania. Disponível em: < Http://real.wharton. upenn.edu/ duranton/Duranton_Papers/Current_Research/MSA_Colombia.pdf> Acesso em: 4 jan 2015.

FREY, W. H. e SPEARE, Jr, A. (1992). Metropolitan Areas as Functional Communities: A Proposal for a New Definition. Research Report, Population Studies Center, University of Michigan USA.

GOUVÊA, R. G. (2005). A questão metropolitana no Brasil. Rio de Janeiro, FGV.

IBGE (2010). Censo demográfico 2010. Rio de Janeiro, IBGE.

(2015). Arranjos populacionais e concentrações urbanas no Brasil. Rio de Janeiro, IBGE.

IPEA, IBGE. UNICAMP/IE/NESUR. (2000). Caracterização e tendências da rede urbana do Brasil: configurações atuais e tendências das redes urbanas. Brasília, IPEA, v. 1, Série de 6 volumes.

JARDIM, A. de P. (2011). "Reflexões sobre a mobilidade pendular". In: OLIVEIRA, L. A. P. de e OLIVEIRA, A. T. R. de. Reflexões sobre os deslocamentos populacionais no Brasil. Rio de Janeiro, IBGE.

JARDIM, A. de P. e ERVATTI, L. R. (2007). Migração pendular intrametropolitana no Rio de Janeiro: reflexões sobre o seu estudo a partir dos Censos Demográficos de 1980 e 2000. Rio de Janeiro, IBGE.

JULIEN, P. (2000). Mesurer un univers urbaine en expansion. Economie et Statistique. Paris, INSEE, n. 336, pp. 3-33. 
LOBO, C. (2016a). Dispersão espacial da população no Brasil. Mercator, v. 15, n. 3.

(2016b). Mobilidade pendular e a dispersão espacial da população: evidências com base nos fluxos com destino às principais metrópoles brasileiras. Caderno de Geografia, v. 26, n. 45.

LOBO, C.; MATOS, R.; CARDOSO, L.; COMINI, L. e PINTO, G. (2015). Expanded commuting in the metropolitan region of Belo Horizonte: evidence for reverse commuting. Revista Brasileira de Estudos de População, v. 32, n. 2, pp. 219-233.

MORRILL, R.; CROMARTIE, J. e HART, G. (1999). Metropolitan, urban, and rural commuting areas: toward a better depiction of the United States settlement system. Urban Geography, v. 20, n. 8, pp. 727-748.

MOURA, R.; BRANCO, M. L. G. C. e FIRKOWSKI, O. L. C. de F. (2005). Movimento pendular e perspectivas de pesquisas em aglomerados urbanos. São Paulo em Perspectiva, v. 19, n. 4, pp. 121-133.

NOGUEIRA, M.; GARCIA, R. A. e MOREIRA, K. C. (2010). A importância dos fluxos populacionais para compreensão da centralidade urbana: o caso de Sete Lagoas /MG. In: CONGRESSO BRASILEIRO DE ORGANIZAÇÃO DO ESPAÇO E X SEMINÁRIO DE PÓS-GRADUAÇÃO EM GEOGRAFIA. Rio Claro, Unesp.

OJIMA, R. (2011). Fronteiras metropolitanas: um olhar a partir dos movimentos pendulares. Revista Paranaense de Desenvolvimento, Curitiba, n. 121, pp.115-132.

(2016). "Pessoas, prédios e ruas: por uma perspectiva demográfica dos processos urbanos contemporâneos". In: OJIMA, R. e MARANDOLA Jr, E. Dispersão urbana e mobilidade populacional. São Paulo, Blucher.

OJIMA, R.; MARANDOLA JR, E.; PEREIRA, R. H. M. e DA SILVA, R. B. (2010). O estigma de morar longe da cidade: repensando o consenso sobre as "cidades-dormitório" no Brasil. Cadernos Metrópole. São Paulo, v. 12, n. 24, pp. 395-415.

OJIMA, R.; SILVA, R. B. e PEREIRA, R. H. M. (2007). A mobilidade pendular na definição das cidades-dormitório: caracterização sociodemográfica e novas territorialidades no contexto da urbanização brasileira. Cadernos IPPUR. Rio de Janeiro, UFRJ/IPPUR, v. 21, n. 2, pp. 111-132.

PEREIRA, R. H. M. e HERRERO, V. (2009). Mobilidade pendular: uma proposta teórico-metodológica. Rio de Janeiro, Ipea (Texto para Discussão, n. 1.395). Disponível em: <http://goo.gl/Kz6f2Z>. Acesso em: 20 abr 2014.

SOUZA, J. de e BRITO, F. (2008). Expansão urbana de Belo Horizonte e da RMBH: A Mobilidade Residencial e o Processo de Periferização, nos anos 80 e 90. In: XIII SEMINÁRIO SOBRE A ECONOMIA MINEIRA. Anais. Belo Horizonte, Cedeplar, Universidade Federal de Minas Gerais.

TASCHNER, S. P. e BÓGUS, L. M. M. (1986). Mobilidade espacial da população brasileira: aspectos e tendências. Revista Brasileira de Estudos de População, v. 3, n. 2.

U.S. BUREAU OF THE CENSUS (1969). Metropolitan Area Definition: a re-evaluation of concept and statistic practice (rev.). Bureau of the census working paper, n. 28, Washington, D.D. 
